\title{
Distinguish Spoken English from Written English: Rich Feature
} Analysis

\author{
Xiufeng $\operatorname{Tian}^{1}$ \\ ${ }^{1}$ Foreign Language Department, Hebei Finance University, China \\ Correspondence: XiufengTian, Foreign Language Department, Hebei Finance University, No.3188, Hengxiang \\ North Street, Baoding City, Hebei Province, China. Tel: 86-137-3128-7625. E-mail: lisa416@163.com
}

Received: March 28, 2013 Accepted: April 24, 2013 Online Published: June 3, 2013

doi:10.5539/elt.v6n7p72 URL: http://dx.doi.org/10.5539/elt.v6n7p72

\begin{abstract}
This article aims at the feature analysis of four expository essays (Text $\mathrm{A} / \mathrm{B} / \mathrm{C} / \mathrm{D}$ ) written by secondary school students with a focus on the differences between spoken and written language. Texts $\mathrm{C}$ and $\mathrm{D}$ are better written compared with the other two (Texts A\&B) which are considered more spoken in language using. The language features are discussed mainlyin three aspects (which are most salient among the four texts): nominalization, lexical density and grammatical intricacy, and personal pronouns. Through the analysis, the discrepancy between spoken and written language is highlighted. Some relevant pedagogical implications are subsequently drawnand expected to be helpful to thoseteaching academic writing.
\end{abstract}

Keywords: rich feature analysis, academic writing, spoken language, written language

\section{Introduction}

Barton (2004) indicates that rich features "are defined as those features that point to the relation between a text and its context. Rich features have both linguistic integrity (i.e., they are structural features of language, so they can be defined in linguistic terms and then categorized, coded, counted, and otherwise analyzed empirically) and contextual value (i.e., they can be conventionally connected to matters of function, meaning, interpretation, and significance)" (p. 66). The analysis of rich features could be very meaningful if used in students writing. Through the comparison between the weaker and stronger writing, teachers may be able to seek answers to why inexperienced writers usually write awkward sentences or express the meaning rather vaguely. It is also believed that, through rich feature analysis, composition teachers will show much more grounded judgments on students' writing as well as clearer guidance for distinguishing spoken language from conventional written language in academic context.

While practicing writing in an academic context, students usually need a period of time to learn to distinguish spoken language from written language. The novice writers in particular tend to transfer spoken language into academic writing where written language is supposed to be more scientifically used. According to Hammond (1990), young children (from English-speaking background or not) have a weak control of differences betweenthe oral and the written modes of language. What makes it more difficult to learn is that "there is no absolute distinction between the two (spoken and written)" (Carter, 2004).

The two modes of English, namely, spoken and written, are especially confusing for nonnative speakers who are learning English but seldom adequately output it as native speakers do. Take Chinese students as an example, the majority of students in China are required to learn English language from primary school until they get to college. However, English is taken as a subject rather than a language for most of the students because they take examinations for it frequently while rarely use it in their daily life. They are usually unaware of the differences between spoken and written English, which might probably lead to the awkward consequences of writing with spoken language but speaking in written mode. It turns to be of great importance that teachers provide students with clear and necessary guidance for them to avoid misusing the 2 types of language on their writing learning journey.

The four expository essays (texts A, B, C, and D, see appendix) that I am going to analyze in this paper are two sets respectively written by inexperienced and experienced writers of secondary students. According to their teachers, the weaker texts (A \& B) are more of spoken rather than written, which is not considered appropriatein 
academic writing. However, it doesn't help students improve only by marking their paper with "write just the way people speak" or "This gives the impression that you're chatting with someone rather than writing an essay." Possibly, they need more detailed guidance suggestingthat they are "chatting with someone" and how they can write to be like "writing an essay". In this paper, specific features will be further and deeply analyzed on the four expository essays.

\section{Rich Feature Analysis}

Between the two sets of texts (A\&B VS C\&D), there are many significant differences reflecting that texts A and $\mathrm{B}$ are more spoken while texts $\mathrm{C}$ and $\mathrm{D}$ are rather written. These differences lie in the utilization of nominalization, lexical density and grammatical intricacy, personal pronouns (i.e., we, I, you), passive voice, vague language (i.e., something, other things), modal expression (I think), etc. I would like to focus on the first three of them which are more salient features for suggesting the differences between spoken and written language in these four expository essays.

\subsection{Nominalization}

The way spoken language differs from written language lies in their functions. Spoken language describes "actions" while written language expresses "things". Halliday (2002) points out:

"speaking and writing - each one makes the world look like itself. A written text is an object; so what is represented in writing tends to be given the form of an object. But when one talks, one is doing; so when one talks about something, one tends to say that it happened or was done" (p. 344).

Actions usually are described by verbs and things by nouns. When students are weaker in controlling the two types of language, they tend to have more descriptions ofaction in academic writing therefore to frequently use verbs instead of nouns.It will be clearer when we compare the followingexcerpts from Text B and D:

\section{Example 1. Words using in Text B and Text D}

1. Once we get more land, farmers can grow crops to provide us food and medicines, and land is also used to provide housing....we must go ahead with it, and if we do, we will see how much it can benefit our people. (Text B)

2. The clearing of timber would allow for more land to be developed for farming and housing, both of which could yield further economic benefits. (Text D)

In extract 1, 9 verbs are there to describe actions and happenings, but only three verbs in extract 2 . With the same meaning development in the two extracts, No. 2 uses more nouns such as "clearing", "farming, "housing", and "benefits" while the equivalence in extract 1 is almost expressed all by verbs or verb phrases, as e.g. 2 shows us in the following:

Example 2. Words using in Text B and Text D

$\begin{array}{ll}\text { Nouns in extract 2 } & \text { Verbs or verb phrases in extract 1 } \\ \text { farming } & \text { grow crops } \\ \text { housing } & \text { provide housing } \\ \text { benefits } & \text { benefit }\end{array}$

This is not a special case which only exists in these two extracts from texts D and B. It is easy to find out that the weaker texts (texts A \& B) has a lot of verbs but the stronger ones (texts C \& D) have quite a number of noun descriptions for creating more formal and abstracted written language. The nouns in the left column of e.g.2 are converted from verbs or other forms of words. The process of turning words that are not normally nouns into nounsis nominalization (Droga \& Humphrey, 2003). According to Hammond (1990), nominalization turns actions into things and it is"a feature of many written texts, especially those of academic genres, and usually is associated with the build-up of abstraction within the text" (p. 40). Through analyzing the two sets of texts, I have easily figured out that nominalization is more frequently utilized in texts $\mathrm{C}$ (more than 20 words: debate, achievement, offering, capabilities, increase, etc.) \& D (more than 30 words: debate, protection, arguments, examination, clearing, removal, etc.) while there are only few words that have been nominalized in texts A (3 words) and B (7 words). The huge difference between the two sets of texts suggests that the construction of the abstract and formal writing in part due to the process of nominalization which contributes to the typical distinguished features between spoken and written language (Droga \& Humphrey, 2003).

Nominalization is very important in writing to secondary students considering from three aspects. Firstly,when nominalization compresses more information into one word or one nominal group, it can be further pre- or post- 
modified (e.g., "benefit" in the sentence of extract 1 "how much it can benefit our people" is a verb. While it is turned into noun as appearing in extract 2 "further economic benefits", it has two pre-modifiers through which more information is compressed into a phrase instead of a clause) and this could make the writing more abstract and condensed. Secondly, nominalization is used in reading materials of most subjects so as to pack more information into the texts. This is what students will encounter in secondary school learning. It can be quite helpful to them to "use nominalization to demonstrate that they understand the more abstract concepts in these subjects" (p. 99). Finally, nominalization contributes to a clear structure and organization since it can be used in short but more information packed headings, paragraph previews and even texts, which can guide readers to find what the text is talking about easily. (e.g., "deforestation" in the title of texts C \& D provides readers a clear picture of "removing forests from ...").

\subsection{Lexical Density and Grammatical Intricacy}

The abstraction of written language does not only lie in nominalization but also in lexical density which, according to Halliday (2002), "is the proportion of lexical items (content words) to the total discourse" (p. 329). The extent of the density (higher or lower) is due to the language type of the texts. Usually spoken language carries less lexical items in clause but written language is on the opposite. The first set of students' texts (A\&B) which teachers think of as more spoken is clearly lower in lexical density compared with the other set of texts $(\mathrm{C} \& \mathrm{D})$ :

Figure 1. Lexical density in the four texts ("LD" means "lexical density")

Text A: Average LD 108:44= about 2.5

Text B: Average LD 99:47= about 2.1

Text C: Average LD 139:24= about 5.8

Text D: Average LD 146:26= about 5.6

The discrepancy between the two sets explains the teacher's comments on texts (A\&B) about "more spoken" or "like chatting with people" in that the lexical density of the second set of the texts is more than 5, twice as many as the first set, as figure 1 suggests. A specific example of lexical density analysis is given as follows:

Example 3. Lexical density analysis

3. To all the parents out there, I'd like to say / that we cannot afford / to ignore this problem/ but must grasp it /and face it head-on /so that the situation in our schools will be fixed./ (text A) (Average LD 10:6= about 1.7)

4. There has been an ongoingdebate in the localpress about the standard of currentschoolleavers, / with especiallyemployersinsisting/ that youngpeople who leaveschool today have a lowerlevel of educationalachievement than in the past./ (text D) (Average LD 20:3= about 6.7)

The words underlined are lexical items which "carry the content of the text" (Hammond, 1990, p. 33). Apparently, more lexical items appear in each clause of sentence 4 which is extracted from text D, but relatively there are more grammatical items which provide no information but only "establish and maintain the relationships between the lexical items" (p. 36) in sentence 3 extracted from text A. These two sentences are just selected to illustrate their lexical identity and not less simple or more difficult than other sentences within their respective texts (A and D). The analysis above shows that text A is less lexically dense than text $\mathrm{D}$. It is well known that reading activity can be done recursively, and the readers can reread the texts time and again until they get the needed information; but when the audience are informed through listening, e.g., in speech delivering, probably they won't be able to decode lots of information in a very short time. And this explains that written language tends to be more lexically dense while spoken language is the opposite. Therefore in e.g. 3 , sentence 4 is more written partly because more information is compressed into the lexical items in its clauses while sentence 3 tends to be spoken with sparse sentence construction. This contributes to the perception that written language is denser in information distribution than spoken language.

Lexical density is one of the salient features to distinguish written and spoken language,but as Hammond (1990) points out, each of them (spoken or written) is complex in its own way, while written is complex in lexical items, spoken is intricate in its clauses.Although sentence 3 is less dense in lexical items than sentence 4, it is rather complex considering from the grammatical structure of the sentences. 
Example 4. Analysis of grammatical structure

3.

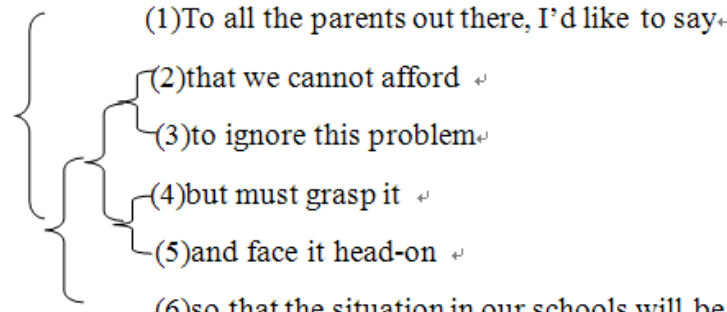

(6)so that the situation in our schools will be fixed. (1)There has been an ongoing debate in the local press about the standard of current school leavers,
(2)with especially employers insisting
(3)that young people who leave school today have a lower level of educational achievement than in the past.

While both of the two sentences contain almost the same number of words, sentence 3 has 6 clauses but sentence 4only has 3. As it is shown above in e.g. 4, the relationship between clauses in sentence 3 is more complex than it is in sentence 4 . There are four levels of relationship as indicated by the brackets on the left side of the clauses of sentence 3 but only 2 levels for sentence 4 . At the first level, clauses (2) and (3) are closest, and the same with (4) and (5); at the second level, clauses (2) and (3) are added to (4) and (5); at the third level, clauses (2) and (3), (4) and (5) are added to clause (6); at the fourth level, clause (1) is added to clauses (2) and (3), (4) and (5) and clause (6) to form the whole sentence 3 which is absolutely complex in clauses relationship. Other than sentences 3 , the other sections of texts $\mathrm{A}$ and $\mathrm{B}$ are even more intricate in this way, while texts $\mathrm{C}$ and $\mathrm{D}$ are in the same situations with sentence 4. This is in accordance with thecharacteristics of spoken and written language, as what Hammond (1990) states in his article: "while written language is more complex than spoken language in terms of lexical density, it is also true that spoken language is more complex than written language in terms of its grammatical intricacy" (p. 41). If the teacher could explicitly express to the writers (of A\& B) the characteristics of both written and spoken language related to lexical density and grammatical intricacy, text A and B could be written better than what they originally present.

\subsection{Personal Pronouns}

Written language used in school context "plays the major role in making meaning, so its resources have to be expanded beyond those resources needed for everyday interaction to take on the more technical and abstract meanings necessary for construing academic knowledge" (Schleppegrell, 2004). Relatively, compared with the abstract and monologic characteristics of written language, spoken language is more dialogic in nature and interpersonal. A dialogue usually involves more than one participant for interpersonal communicating in which first and second person pronouns are frequently used.Oppositely, the monologic written language doesn't need immediate feedback from the participants (its' readers) thus to use less first and second person pronouns. The utilization of first and second person in spoken language mainly expresses the speakers' desire of interaction with their participants or audience so as to get closer to them. However, in a piece of academic writing, since the writer may not share with his/her readers the same physical context or background, the two sides tend to keep a certain distance from each other. Personal pronouns are sometimes used but not frequently. Therefore, the frequency of using first and second personal pronouns is one characteristic that we count for the discrepancy between spoken and written language.

As for the four expository essays, the first set of texts (texts A\&B)which are considered as weaker ones have frequently used the first and second personal pronouns (i.e., I, we, you, us...) while the second set (texts B\&D) has none.

Table 1. Times of appearance of personal pronouns in the four essays

\begin{tabular}{llllllllll}
\hline & \multicolumn{3}{l}{ First person } & & \multicolumn{2}{c}{ Second person } & \multicolumn{2}{c}{ Third person } \\
& I & we & our & us & my & you & they & their & them \\
\hline Text A & 10 & 3 & 4 & 3 & 1 & 4 & 1 & 2 & 0 \\
\hline Text B & 4 & 12 & 3 & 4 & 0 & 1 & 3 & 1 & 0 \\
\hline Text C & 0 & 0 & 0 & 0 & 0 & 0 & 2 & 3 & 0 \\
\hline Text D & 0 & 0 & 0 & 0 & 0 & 0 & 1 & 2 & 1 \\
\hline
\end{tabular}


Obviously, both texts A and B prefer use more personal pronouns, especially those in first person. Text A uses "I" 10 times and text B uses "we" 12 times which makes the two texts more personal rather than academic: e.g., "I believe, and I am sure most of you do, that young people today are not ..." (text A); "We must go ahead with it, and if we do, we will see how much it can benefit our people" (text B). It sounds like a speech that the writers are presenting their ideas in front of the audience who are sharing the same physical context with them and will probably provide feedback towards what the speakers are talking about. When the first personal pronoun is used in vague language, the texts become more spoken: e.g., "I believe, and I am sure"; "I think"; "we will see". However, writing in academic genres doesn't necessarily need interaction between writers and readers through frequently using personal pronouns. Most of the time, the monologic nature of written language will keep its audience a little farther away from what it presents. Texts C and D haven't used any first or second personal pronouns but only third personal pronouns for reference towards the previously used nouns: e.g., "While the standard of some current school leavers may be low, the majority of students succeed in completingtheir academic studies..." (text C); "To put their main arguments in a nutshell..."(text D). "their" in the sentence from text Crefers to the nominal group "the majority of students" and the one in the sentence from text D refers to "conservationists" and "the logging industry" which appeared previously in that paragraph. As Droga and Humphrey (2003) point out that reference of this kind "is common in written language and is often used to avoid repetition" (p. 105). Although texts A and B also have pronouns as reference, the utilization of first personal pronouns is more salient in reflecting their tendency of language use, namely more spoken.

\section{Pedagogical Implications}

Through analyzing the rich features of students' writing in terms of spoken and written language, I myself become clearer what the nature of written language is and that is of great importance to teaching students academic writing. While students are learning to write, using spoken language in writing academic essays seems very common. To have a good control of written language helps them not only in writing but also in commanding other school subjects because what they may confront with in reading of school context are rather formal and abstract articles. It is the teachers' responsibilities to offer help to them.

Yet teachers do not usually know how to offer their help to students in writing classes. While reading and correcting students' essays, simply marking some grammatical mistakes and briefly commenting on the paper like "vague", "awkward", and "good" doesn't enhance students' writing skills. It is quite possible that students ignore what teachers have marked because they don't understand what those comments mean. However, if the teacher not only shows where the problems are but also explains in detail that why the language is problematic and how to avoid those problems next time, students will probably gain more in this writing task. This is not easy to do for some teachers because they may not know how to specifically express the idea that why the language is problematic and why it is more spoken; but rich feature analysis provides teachers with experience of finding typical characteristic of the language therefore to teach students in academic writing.

Considering PRC EFL teaching context, what should be noticed is that teachers are quite likely to mark grammatical or spelling mistakes on students' writing rather than vague or inappropriate language problems because both teachers and students mainly tend to focus on grammar instead of proper language usage in English writing. Accordingly, raising their awareness (especially the teachers' perception) of the nature of written language is much of significance for English learning.

\section{References}

Barton, E. (2004). Linguistic discourse analysis: How the language in texts works. In C. Bazerman, \& P. Prior (Ed.), What Writing Does and How it Does it (pp. 57-82). Mahwah, N.J.: Lawrence Erlbaum.

Carter, R. (2004). Grammar and spoken English. In C. Coffin, A. Hewings, \& K. O’Halloran (Ed.), Applying English Grammar (pp. 25-39). London: Open University.

Droga, L., \& Humphrey, S. (2003). Creating well organised and cohesive texts. Grammar and Meaning: An Introduction for Primary Teachers (pp. 85-109). Berry, NSW: Target Texts.

Halliday, M. A. K. (2002). Spoken and written modes of meaning. On Grammar: Volume 1 of the Collected Works of M. A. K. Halliday (pp. 323-351). London: Continuum.

Hammond, J. (1990). Is learning to read and write the same as learning to speak? In F. Christie (Ed.), Literacy in a Changing World (pp. 26-53). Hawthorn, Victoria: ACER.

Schleppegrell, M. (2004). Linguistic features of academic registers. The Language of Schooling (pp. 43-76). Mahwah, N.J.: Lawrence Erlbaum. 


\section{Appendix}

\section{Pairs of Weaker (Texts A \& B) and Stronger Argumentative Essays (Texts C \& D) by Secondary School Students}

\section{Text A. Has there been a decline in the quality of education?}

1. As you know, people have recently been writing in the newspapers about the standards of current school leavers. I support all those writers who have been arguing that we young people do less well academically, because as a student myself I can see it happening.

2. I believe, and I am sure most of you do, that the young people today are not getting a fair go with the low educational standards in many schools. In my school I have noticed that there is a big problem with discipline. Every day you can see that many teachers are not able to keep their students in check, and so their classes become chaotic, and then some students become so disruptive that the others cannot concentrate and have trouble learning.

3. Also many of us can't even read, write or do math properly, which leaves us with poor exam marks. I think that every child must be taught these skills and when we reach the upper grades we should go further and learn more advanced things. But this is not happening, and what makes it worse is that our teachers are not held accountable, and they are also often blind to the fact that the number of illiterate people in our country is rising.

4. To all the parents out there, I'd like to say that we cannot afford to ignore this problem but must grasp it and face it head-on so that the situation in our schools will be fixed. I am one of the students affected, and so are most of my classmates, and I urge you to do something about it. Let us defend the educational standards of our young people, look into the aspects I have mentioned and make sure that things will be better in the future.

\section{Text B. In support of deforestation}

1. Currently a lot of people are debating whether or not we should remove trees from our rainforests. I support those who believe that this is the way for us here to go.

2. I am all for deforestation because I think that we have to remove trees in the rainforests to acquire more land. Once we get more land, farmers can grow crops to provide us food and medicines, and land is also used to provide housing. The trees of the rainforests give us building material so as trees are cut down, the land provides the area for houses, which are built from the felt trees. We have to build those houses because our population is growing and they need to have shelter from the harsh weather in Australia.

3. For children to have a good education they need to go to school to learn. To learn you definitely need paper because we use it to write on and it's also necessary for the books we read. Paper is made from trees, which therefore need to be cut down. We also get other things from the trees in the rainforest, like fuel. Also let's not forget that the trees are cut down by loggers. These people would be out of a job if there was no deforestation, and they wouldn't be able to support their families. And deforestation helps our economy because we can buy and sell all those products from the rainforests. So that's why I think we all must support deforestation. We must go ahead with it, and if we do, we will see how much it can benefit our people.

\section{Text C. Has there been a decline in the quality of education?}

1. There has been an ongoing debate in the local press about the standard of current school leavers, with especially employers insisting that young people who leave school today have a lower level of educational achievement than in the past. However, this issue is highly complex and must be considered from various angles.

2. Most schools today are more concerned with academic achievement and the offering of a range of course choices than ever before. In this day and age many educational pathways are open for students of different interests, background and capabilities. On the one hand, combined classes and honoursprogrammes allow gifted students the opportunity to realize their full potential. On the other hand, there are learning support programmes which give students with learning difficulties the extra encouragement that they need to reach the next level of their education. This has not only led to better exam results, but also to an increase in the capabilities students have in the areas of reading, writing and mathematics.

3. Furthermore, just because the cane is not used in schools any longer, this does not mean that discipline standards have fallen dramatically. Punitive measures like detention and internal suspension are more than enough to stop most problem students. If one adds to these measures incentives like enrichment programmes for students that have behaved to an acceptable standard to this, the problems with discipline can be quite readily 
solved.

4. While the standard of some current school leavers may be low, the majority of students succeed in completing their academic studies with a higher level of educational achievement than in the past. Looking at the issue objectively, the quality of education received and the standard of achievement are not dropping; they are equal or even superior to those of the past.

\section{Text D. In support of deforestation}

1. In recent years there has been a great deal of debate in Australia over whether rainforests should be logged. While conservationists argue for the protection of the rainforests as habitats for valuable plants and wildlife, the logging industry has made a case in favour of strategic deforestation. A close examination of the arguments of the proponents of the two sides reveals that the issues at stake are by no means straightforward. However, this essay considers the arguments made by the logging industry as the more convincing of the two and will present them in the following.

2. To put their main arguments in a nutshell, those in the logging industry contend that it is necessary for some rainforest areas to be removed because of the employment opportunities which their removal can create and the economy which can be sustained as a result. The clearing of timber would allow for more land to be developed for farming and housing, both of which could yield further economic benefits. Each of these arguments will be elaborated in turn.

3. As for employment opportunities, it is likely that they would increase considerably with the removal of timber from some rainforest areas and with its subsequent processing. Once removal and processing have occurred, the designing and building of houses or roads as well as the planting of crops for both food supply and medicinal purposes could be set in motion. For these various tasks a large number of people would be needed and could thus find employment.

4. In addition to opening opportunities for work, the removal of trees in some parts of the rainforests could also assist in the securing of land for farming and housing in cost-effective ways. Housing provides the necessary homes for a steadily and rapidly increasing population, and farming can provide a wide range of products that are required for everyday living such as meat, milk, vegetables and wool. These are all vital necessities for Australia's continuing economic development and the improvement of the standard of living of its population.

\section{Copyrights}

Copyright for this article is retained by the author(s), with first publication rights granted to the journal.

This is an open-access article distributed under the terms and conditions of the Creative Commons Attribution license (http://creativecommons.org/licenses/by/3.0/). 